City University of New York (CUNY) CUNY Academic Works

2018

\title{
A call for Second-Generation Cryptocurrency Valuation Metrics
}

Edward Lehner

CUNY Bronx Community College

Louis Carter

Best Practice Institute

John Ziegler

\section{How does access to this work benefit you? Let us know!}

More information about this work at: https://academicworks.cuny.edu/bx_pubs/52

Discover additional works at: https://academicworks.cuny.edu

This work is made publicly available by the City University of New York (CUNY).

Contact: AcademicWorks@cuny.edu 


\begin{abstract}
This article builds on the body of work that has depicted cryptocurrency as a model for science and higher education funding. To that end, this work examines the degree to which one or more cryptocurrencies would need to be adopted and achieve a network effect prior to implementation of such a funding model. Empirical data from three different cryptocurrencies were examined. The current work deploys generalized autoregressive conditional heteroskedasticity (GARCH) to analyze stochastic volatility. This work contends that the examined coins are likely overdistributed and too volatile, thereby limiting the wealth generation possibilities for funding science or higher education. Additionally, based on the GARCH analysis, this work highlights that cryptocurrency pricing metrics and valuation models, to this point, maybe insufficiently complex to persuade institutional investors to seriously allocate capital to this ecosphere.
\end{abstract}

\title{
Keywords:
}

Cryptocurrency; higher education funding; GARCH; network theory; science funding; two-sided marketplace network effect; Metcalfe's law. 
The phenomenon of the underfunding of science research specifically, and of higher education more broadly, is a significant and pressing issue whose complexities require innovative approaches to begin to ameliorate the persistent diminishment of financial resources. Although science research and higher education funding are, admittedly, separate and fund specific fields with distinct practices and obstacles, this work investigates how an enacted twosided network effect could provide alternative portfolio diversification to fund both areas. By continuing previous work on portfolio modeling using cryptocurrency (Lehner et al., 2017) and the conceptual framing of cryptocurrency-based funding (Lehner and Ziegler, 2018), this work further examines the importance of an enacted two-sided market effect as it relates to the type of cryptocurrencies to effectively augment science research and higher education funding. More specifically, we employ cryptocurrency data to examine the degree to which three different currencies have achieved a network effect, in which additional users create additional value, and whether these currencies could serve as viable academic funding streams.

We elucidate this position in seven distinct sections: 1) science research and higher education funding as a human right and subsequent alignment with budgetary realities; 2) cryptocurrency as wealth generator, enacting disruption of science research and higher education funding; 3) examination of cryptocurrency volatility and pricing metrics; 4) specific examination of Bitcoin, Dash, and PIVX; 5) and limitations, directions for future research, and conclusions.

\section{Reclaiming Science Research and Higher Education as Public Goods and Human Rights}

The funding of science research and higher education has been closely intertwined with U.S. politics since their origins, an interrelationship that produces undesirable influences that might be mitigated by alternative funding sources. Lehner et al. (2017) argued that U.S. scientific research currently models a version of private equity investment, as various stakeholders 
compete for the intellectual property that government- and corporate-sponsored research produces. Consequently, researchers must always consider how best to position external stakeholders as they pursue work internally. The results of their research are likely to be published in the walled gardens of commercially controlled academic journals (Lehner and Finley, 2016), all while under the constant threat of diminished funding and other resources. This work centers on alternative funding; however, its fundamental underpinnings more closely align with the argument that science and higher education are fundamental human rights and that the primary purpose of both is to benefit the public.

Giroux (2015, 2017), Ioannidis (2017), and Kennedy (2012) contended university funding for scientific research is tied to a host of implicit and often underexplored corporate factors in complicated ways. Chomsky (2011) noted that scientific researchers find themselves at a troubling impasse, with austerity measures and conservative politics at one end of the spectrum and the need to advance scientific inquiry for societal benefit on the other.

Aud et al. (2010) noted, in their report for the National Center for Education Statistics, that federal funding for higher education is declining, despite a growing number of student loans. In addition, the Pew Foundation (2012) underscored that federal funding for higher education has consistently declined during a decade of economic growth. Echoing the complex negotiations inherent in the funding of science, U.S. higher education, as reported by the Pew Trust (2015), may be approaching an unprecedented crisis that may lead to college and university closings (Barr and McClellan, 2018; Christensen et al., 2011; Christensen and Eyring, 2011; Grier, 2015; Roger and Baum, 2017). Noting the paradox of diminished federal funding while nearly every other sector of the economy has flourished, Leachman et al. (2016) emphasized that this precipitous underfunding has led to more state responsibility for higher education and more 
student debt. Hillman (2014), building on two decades of scholarly literature on student loan defaults (Aud et al., 2010; Christman, 2000; Dillon and Carey, 2009; Dynarski, 1994; Gladieux, 1995; Gladieux and Perna, 2005), highlighted that as students bear more of these costs, their debt responsibilities become overwhelming, leading to mass levels of student loan defaults. The probability of massive student loan defaults, as Roger and Baum (2017) keenly noted, is an underresearched issue that will likely have damaging effects not only within higher education but throughout the American economy.

In contrast to the language and epistemology of consumer capitalism—as Barr (2017), for example, uses in discussing educational costs - framing the funding of science and higher education as human rights advances pertinent concerns that are not immediately mediated or constrained by either a profit motive or the budgetary limitations imposed by the dominant paradigm of fiscal austerity. For instance, in science research, Luke et al. (2018) contended that a government should consistently fund basic science research because it collectively provides value to both the nation-state and the individual (pp. 77-78). Parallel to this argument, McMahon (2009, p. 6) contended that a supportive higher education policy substantially contributes to the public good by affording career opportunities that may not otherwise be available to students and societal benefits to the community at large.

However, communitarian arguments centered on beneficence (Belmont Report, 1979; Emdin and Lehner, 2006) have found increasingly less support from the political and ideological power factions. For example, since the election of U.S. President Donald Trump in 2016, the National Institutes of Health has been repeatedly slated for dramatic budgetary cuts. The Centers for Disease Control and Prevention, the Food and Drug Administration, and the Environmental Protection Agency, among others, face similar proposed reductions. Yet, it remains paradoxical 
to frame these cuts as austerity measures, since at the time of writing the U.S. economy is experiencing a full 8-year bull market. Nonetheless, as Kaiser (2018) noted, significant scientific research funding has been consistently positioned for cuts primarily because of ideological differences between the Trump administration and the long-tail, theoretically bipartisan value of scientific research. The notion that a single administration can fundamentally reframe the mission, ideological underpinnings, and logic frameworks of decades of scientific research has many within the research community greatly disturbed (cite). Indeed, the underfunding of science is often contextualized within a broader rise in authoritarian populism (Peters, 2018), combining the neoliberal agenda of privatizing public goods (Greenwood and Levin, 2011) with political messaging aimed at the average American citizen (Kazin, 2016; Mead, 2017). For example, Kaiser (2018) has specifically highlighted how cancer research, an American medical concern that one would expect to cross political lines, may be underfunded predicated on the administration's framing of cancer research not as a societal good but as putative governmental waste. Political allegiances aside, should not an agency such as the National Institutes of Health, which is tasked with biomedical and public health research, be shielded from extensive budgetary cuts, since its mission is so closely tied to the welfare of the citizens that the government supposedly exists to serve?

As discussed in Lehner et al. (2017), the funding of science research should ultimately supersede epistemological, ideological, and political differences. As Lehner and Ziegler (2018) noted, higher education funding should similarly be viewed as a societal good exempt from austerity measures and funded differently than the traditional annual budget. Extending these rights to the individual may of course be both a cause and effect of benefit to the public good. For example, Gittleson and Usher (2017) argued that education should be extended to all people 
living in the U.S., primarily for the benefit of the nation-state, although the individual would also significantly benefit. Building on the framework of Gittleson and Usher, Gilchrist (2018) contended that higher education embodies catalytic attributes that fundamentally advance the individual and the nation-state simultaneously; yet, austerity proposals abound, often framed as common-sense populism, even though such measures are frequently actual impediments to economic growth. For example, Rickman and Wang (2018) explained how extreme cuts to education funding tend to be based on the underlying ideological principles informing state administrations, as demonstrated by two midwestern state governments, interrogating the populist notion that austerity measures help to stimulate the economy. Providing an in-depth quantitative analysis of the economic impact of austerity funding, the authors concluded "rather than experiencing stimulative growth effects from reductions ... [states,] if anything, experienced negative economic multiplier effects from reduced state and local government spending" (Rickman and Wang, 2018, pp. 53-54).

Finally, as informed by the long tradition of Bildung (Levin and Greenwood, 2011), this work envisions catalytic change (Emdin, 2010; Kincheloe, 2010; Lehner, 2007; Lincoln and Guba, 1989; Roth, 2010; Tobin, 2010) through the deployment of cryptocurrency as an agent to disrupt and eventually reconfigure conceptualizations of science and higher education funding. To reiterate, science research and higher education funding must be positioned as fundamental rights, primarily because when properly oriented both greatly advance the concerns of the individual and society. Levin and Greenwood (2017) underscored how universities and the social sciences could be revitalized by deploying, as a fundamental mission, the principles of community beneficence, growth, and self-cultivation. Situating their work in a critique of the neoliberal university that mirrors corporate structures, Greenwood (2008) called for university 
researchers to engage in their work in responsible and socially meaningful ways, noting that “academic professional organizations ostracize activist scholars through a combination of selfpolicing censorship and the imposition of intellectual frameworks inimical to activist scholarship" (p. 319). In the tradition of activist scholarship, building on the ideal of Bildung, we formulate that the research act is a lifelong process that is meant to both influence and initiate social change.

\section{Cryptocurrency as Wealth Generator: Enacting Disruption of Science and Higher Education Funding}

By repositioning scientific research and higher education as public goods, more members of the public may become involved, by taking advantage of the potential for cryptocurrencies to produce a network effect. There is little reason to believe that the current march toward everincreasing budget cuts, direct and indirect corporate influence, and the entrenchment of neoliberal austerity as orthodoxy has an end in sight. If anything, under the current administration, much of the United States seems poised to reinforce and extend these policies, even while the federal government looks to undercut moves toward student debt relief and to roll back regulation of predatory for-profit colleges. Countering these trends is vital if we are to increase the ability of educators and researchers to determine the direction of their own work by reducing the extent to which they are beholden to external stakeholders and move toward universalizing the social and individual benefits of scientific research and higher education. Therefore, any alternative mechanisms for funding must be considered. Cryptocurrency offers one such mechanism that may be enhanced by a network effect.

Cryptocurrencies form a class of entirely digital assets based in cryptography and are viewed as a store value (Blau, 2018; Burniske and White, 2017; Burniske and Tatar, 2017; 
Lehner et al., 2017; Lehner and Ziegler, 2018), akin to commodities and precious medals. Having evolved from the open-source code in which Bitcoin was written, cryptocurrencies, including Bitcoin, constitute a "unique asset class - meeting the bar of investability, and differing substantially from other assets in terms of its politico-economic profile, price independence, and risk-reward characteristics. . [and are] subject to the strong network effects of users and developers" (Burniske and White, p. 24). These characteristics make cryptocurrencies strong candidates for financial diversification (Lehner et al., 2017) with potential to generate wealth; they also have the potential to emerge as a mitigator of ongoing disinvestment in college students, U.S. citizens, and the public good.

Before discussing the network effect in relationship to cryptocurrencies as a funding source, this work briefly summarizes an approach to managing a cryptocurrency fund that generates returns via compound interest and coin appreciation. This model used cryptocurrency coins that employ the proof-of-stake algorithm (Lehner et al., 2017), which progresses beyond Bitcoin's proof-of-work algorithm. Successful proof-of-work mining depends on costly computer hardware and an outsized amount of electricity. Removing those barriers allows for more flexibility and perhaps even individual or institutional cooperation in generating returns for funding. The model additionally facilitates flexibility and accessibility by using open-source tools, demonstrating Christensenet al.'s (2011) definition of technological disruption. Finally, the dividend features of proof-of-stake coins can offset extreme price fluctuations in the sometimes volatile cryptocurrency market.

To create the [crypto] fund, a group of academics and bankers purchased an initial group of high-yield coins selected according to valuation metrics developed by members of the group, as well as Google Cloud Project data. Then, open-source tools including Linux's Ubuntu, 
PuTTy, and Unix were employed as part of an investment strategy that involved hosting network full nodes, which entitled the fund to a portion of each block reward. By reinvesting the dividends earned, a practice influenced by Reiss (2017), the model fund generated returns of more than $400 \%$ over 12 months. Researchers or educators using this strategy could apportion returns as needed to both reinvestment and funding, potentially reducing reliance on student debt, grants from government and industry, and state, local, and federal budgets. This shift in funding could help to reclaim for the public good the advantages, economic and otherwise, derived from scientific research and higher education.

\section{Cryptocurrency Stochastic Volatility Modeling}

Having framed this work in the tradition of Bildung, noting that society is the essential beneficiary of science and higher education funding, this paper methodologically centers on cryptocurrency stochastic volatility modeling. To this point, the cryptocurrency asset class lacks full-fledged valuation methods. Current metrics need to be examined and reframed in order to assemble a coherent methodological framework. To this end, we review, in the next section, the relevant cryptocurrency volatility metrics. In reviewing this literature we examine and deploy generalized autoregressive conditional heteroskedasticity (GARCH) modeling as a way to understand what types of coins may fund science and education.

\subsection{Method}

Below, we examine PIVX, Dash, and BTC by employing GARCH, one of the stochastic volatility models, to elucidate the volatility of cryptocurrency markets (Byun et al., 2015). Engle and Bollerslev (1986) detailed how GARCH modeling underscores the way financial markets change, highlighting price volatility during turbulent periods and reverting to price stability during times of market stability. GARCH and other stochastic volatility models have been 
developed to redress some of the complexities with using the Black Scholes options model, which does not afford for volatility over time (Bollerslev et al., 1988). GARCH's statistical modeling is predicated on financial time-series data, underscoring how heteroskedasticity depicts patterns of irregularity and variation in a financial model.

To this point, researchers in cryptocurrency have widely used GARCH to model price fluctuation in the asset class. Dyhrberg (2016), Gronwald (2014), and Katsiampa (2017), as primary examples, all deployed GARCH to frame BTC's, and to a lesser degree, ALTcoins' volatility metrics to determine whether the assets were overbought or oversold. However, Dyhrberg (2016), Gronwald (2014), and Katsiampa (2017), the most highly cited authors who employed GARCH specific to cryptocurrency, used this measure specifically to understanding volatility. Chu et al. (2017), for example, recently argued that GARCH and other related models are the best tools for modeling volatility in the largest and most popular cryptocurrencies.

By bringing forward the work of Chu et al. (2017), Dyhrberg (2016), Gronwald (2014), and Katsiampa (2017), this work deploys GARCH to analyze three different coins and retrospectively examine the models to determine if the coins could provide a starting point for a fund to support science or education. Below, using GARCH, we analyze the historical returns and detail these data in five different charts. The first two charts denote the specific coin's historical market cap and returns through late July 2018. The third chart illuminates the univariate GARCH coefficients, including mu, omega, alpha 1, and beta 1, noting the confidence of the model's fit to studied coins. Chart four uses GARCH to fit a conditional sigma. Lastly, chart five forecasts conditional SD with $95 \%$ confidence within a 20-day window. 


\section{The Results}

\subsection{PIVX}

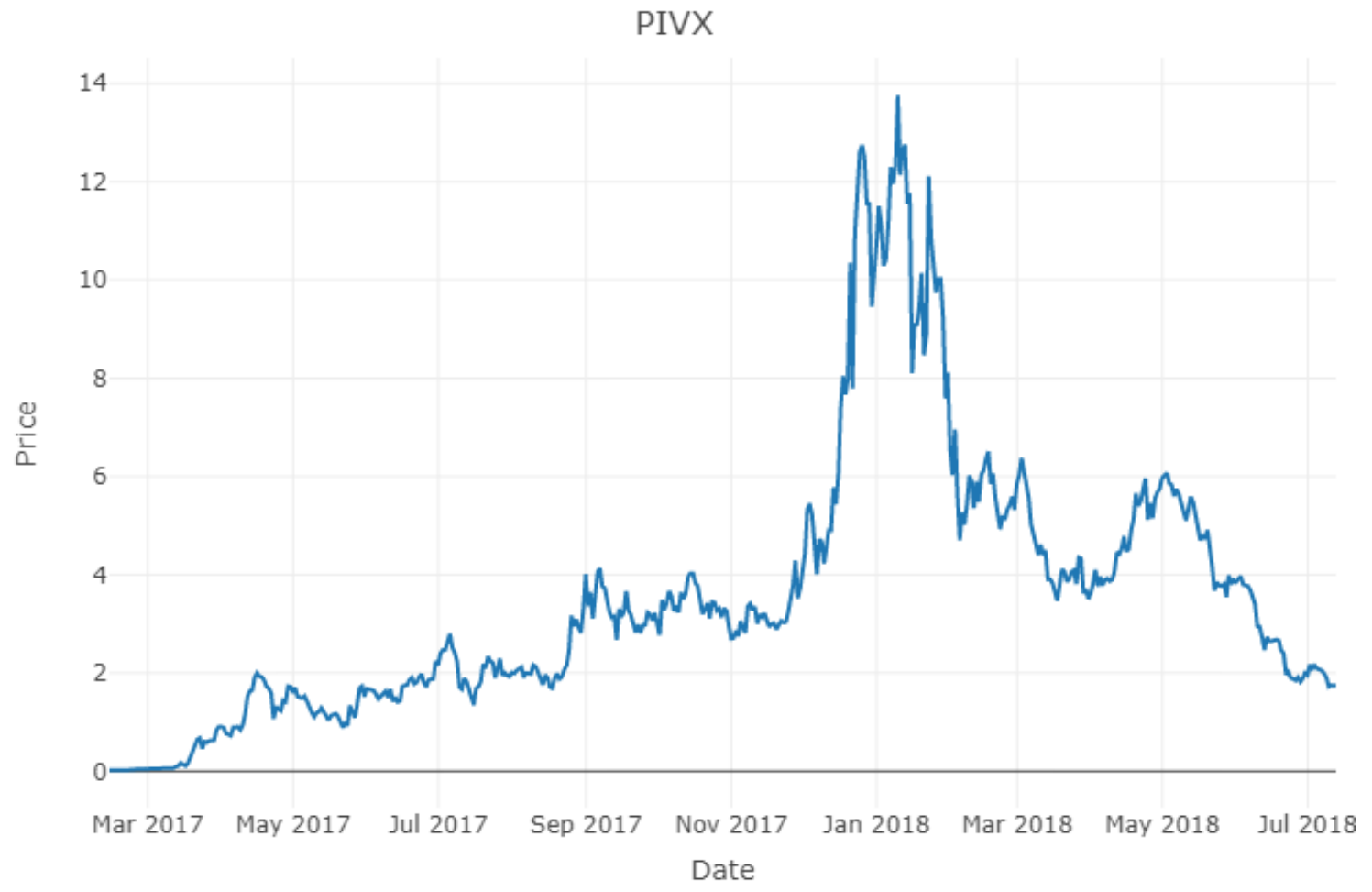

Fig. 1. Figure caption goes here. 


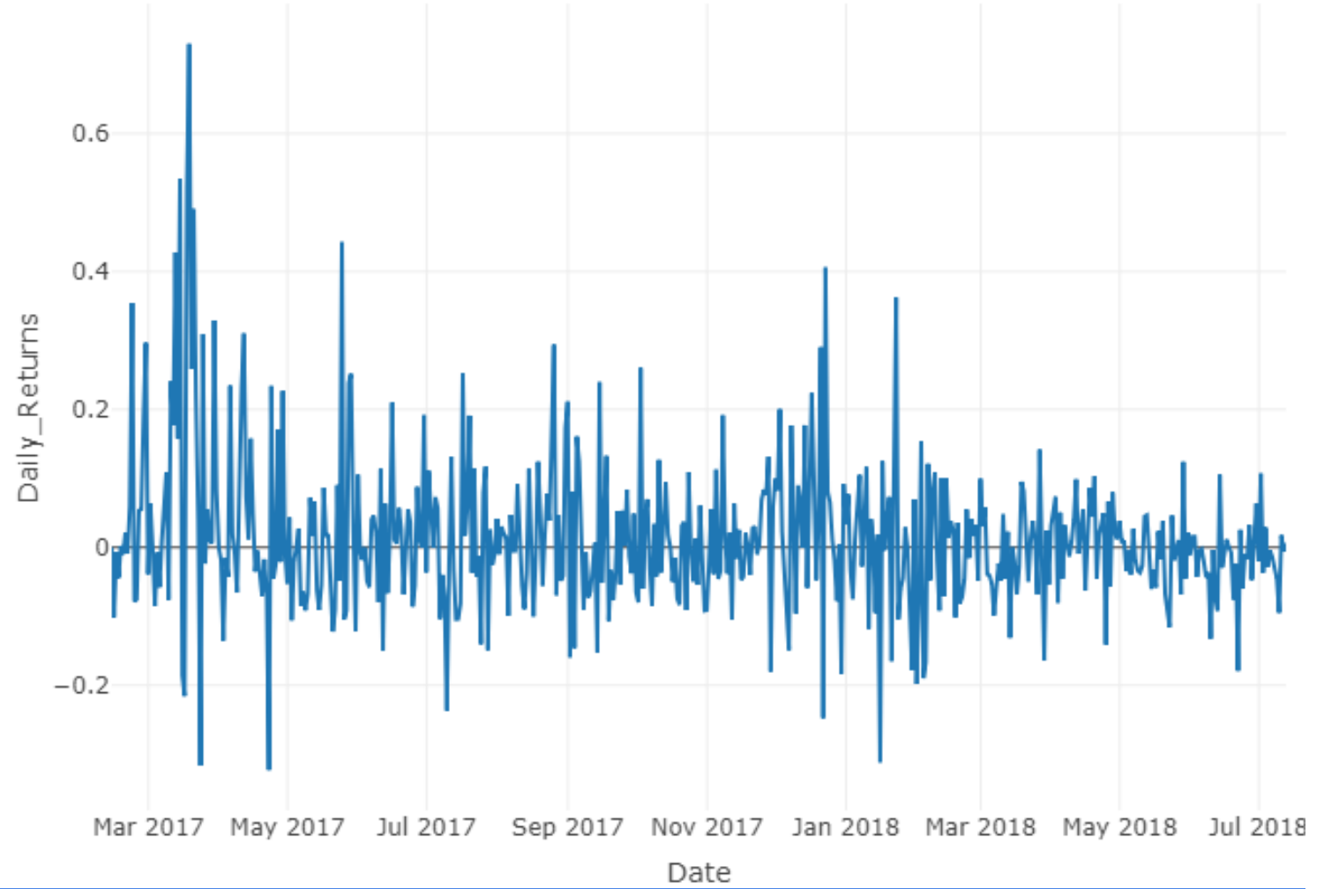

Fig. 2. Figure caption goes here.

Table 1. PIVX coefficients: GARCH $(1,1)$

\begin{tabular}{lcccc}
\hline & Estimate & Std. Error & $\mathrm{t}$ value & $\operatorname{Pr}(>|\mathrm{t}|)$ \\
\hline $\mathrm{mu}$ & 0.0042 & 0.0039 & 1.0695 & 0.2848 \\
omega & 0.0004 & 0.0005 & 0.8649 & 0.3871 \\
alpha1 & 0.1199 & 0.0636 & 1.8859 & 0.0593 \\
beta1 & 0.8461 & 0.0984 & 8.5997 & 0.0000 \\
\hline
\end{tabular}




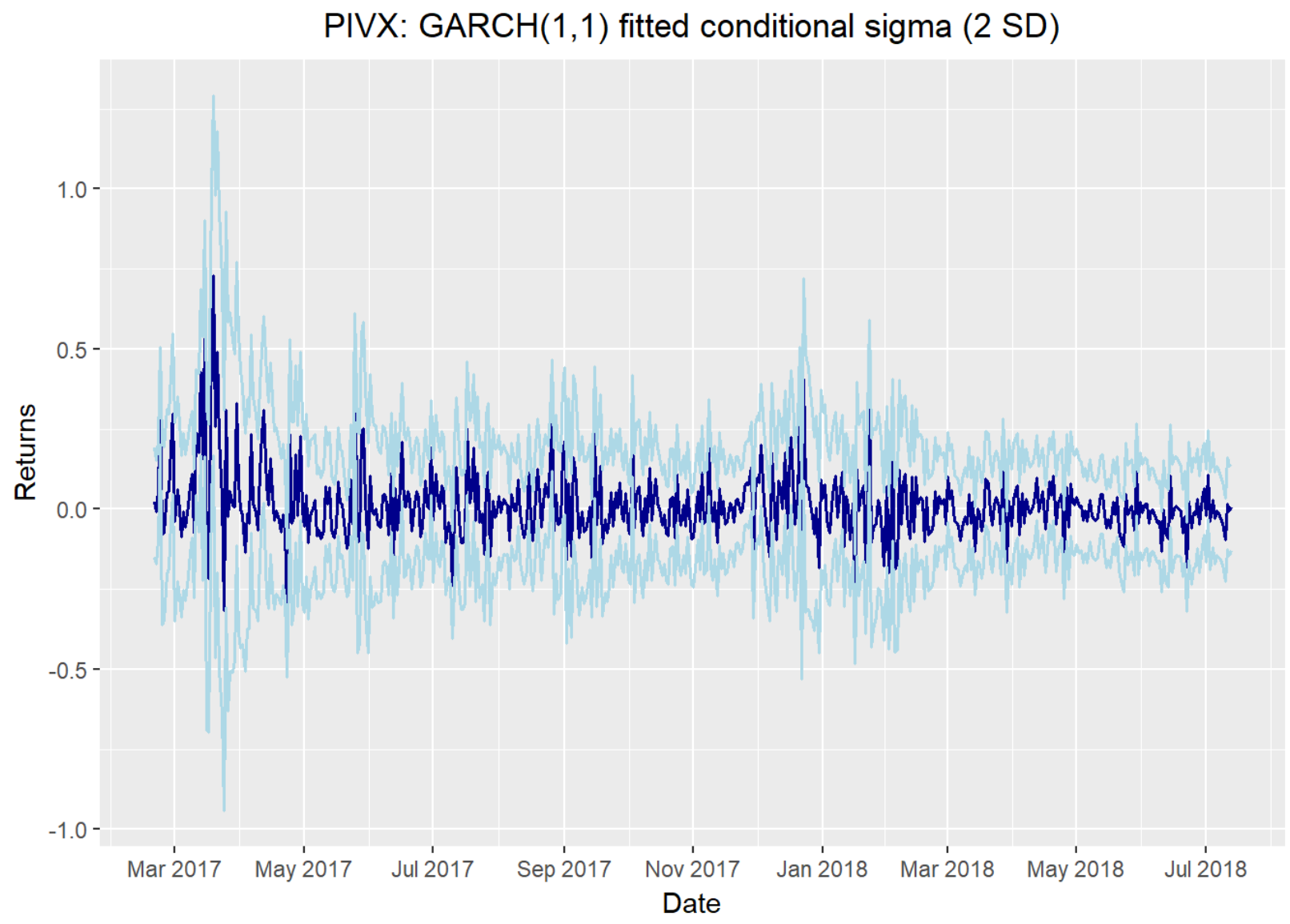

Fig. 3. Figure caption goes here. 
PIVX: Forecast for conditional SD (95\% confidence interval, 20 days ahead)

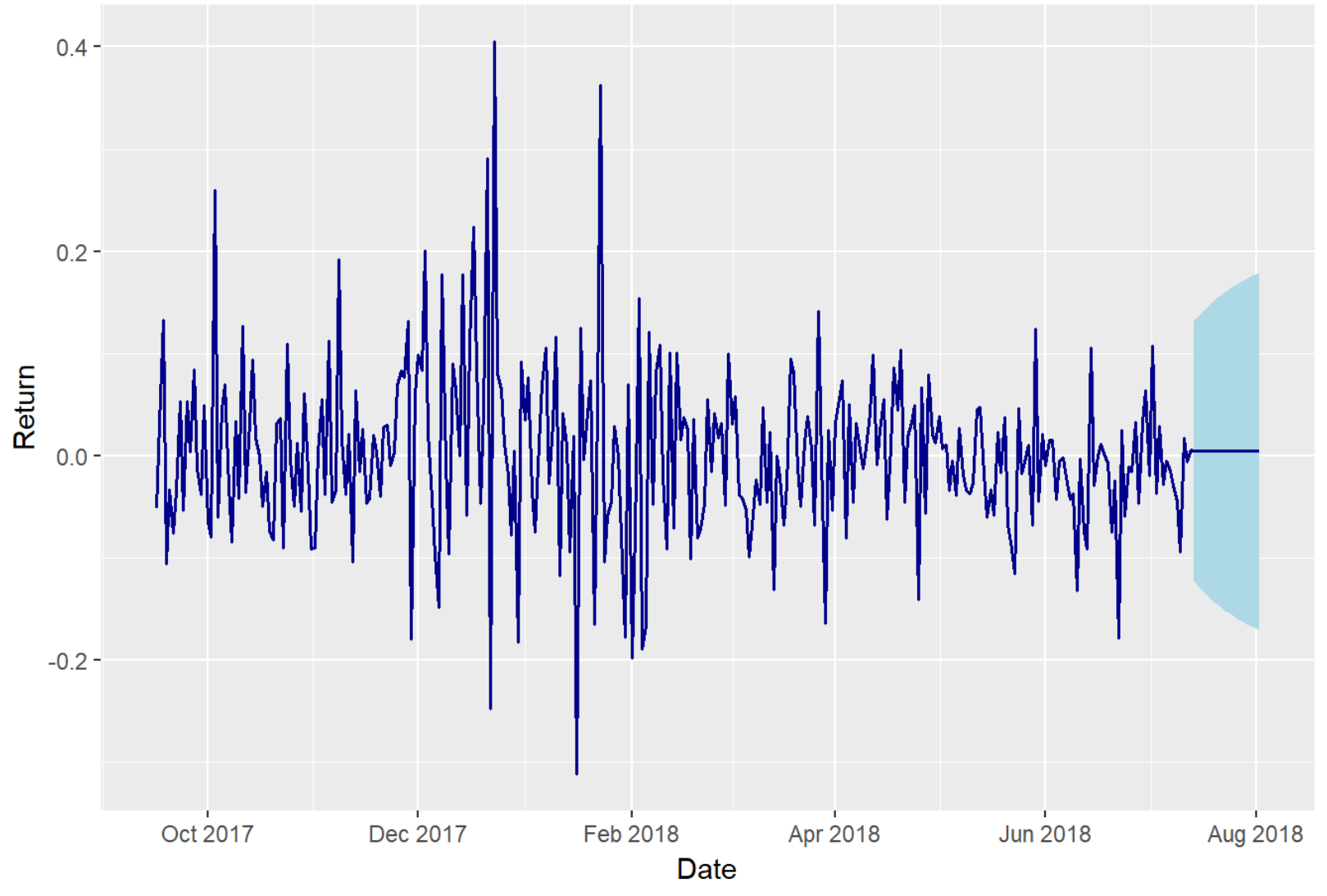

Fig. 4. Figure caption goes here.

\subsection{DASH}




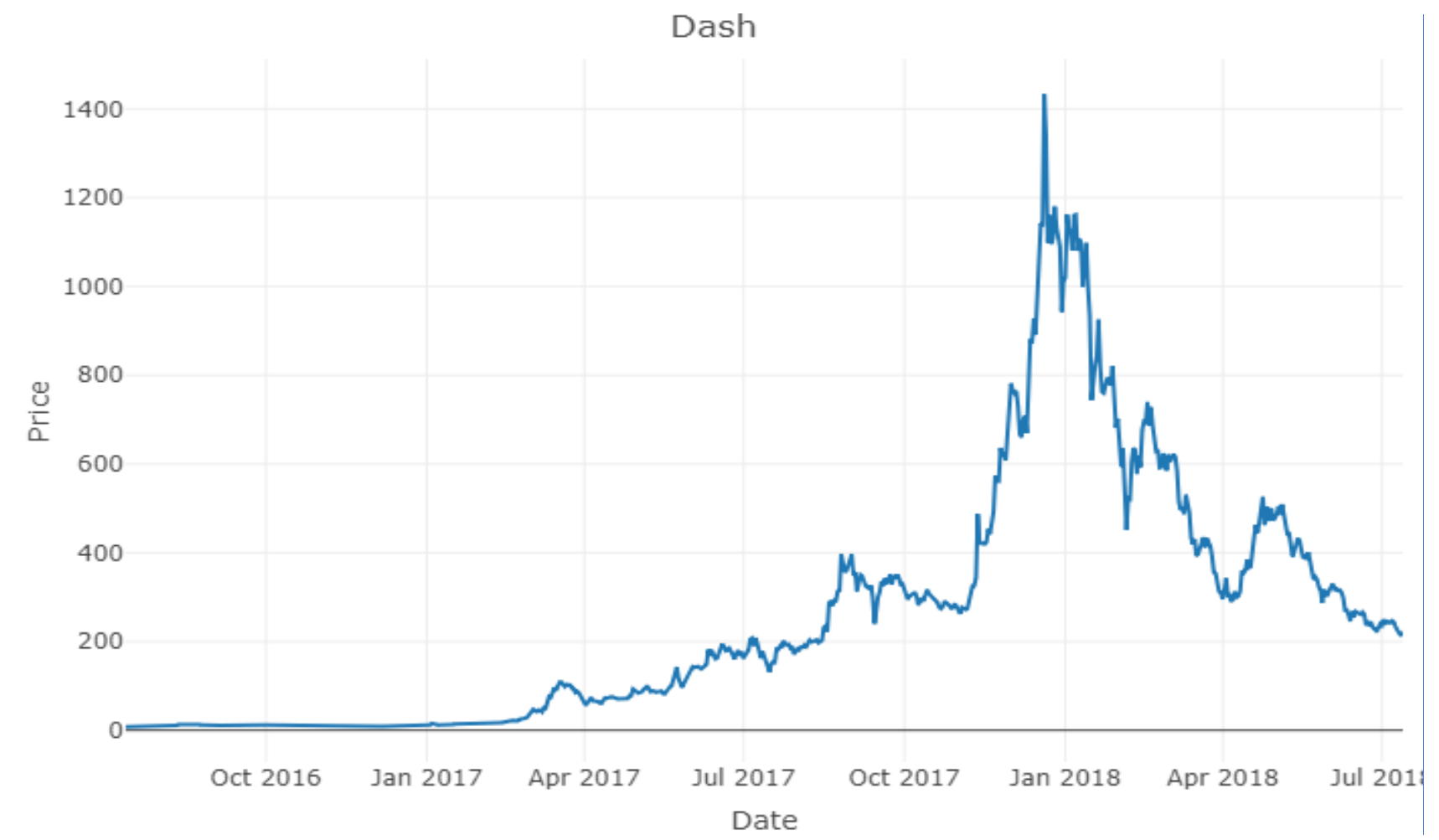

Fig. 5. Figure caption goes here.

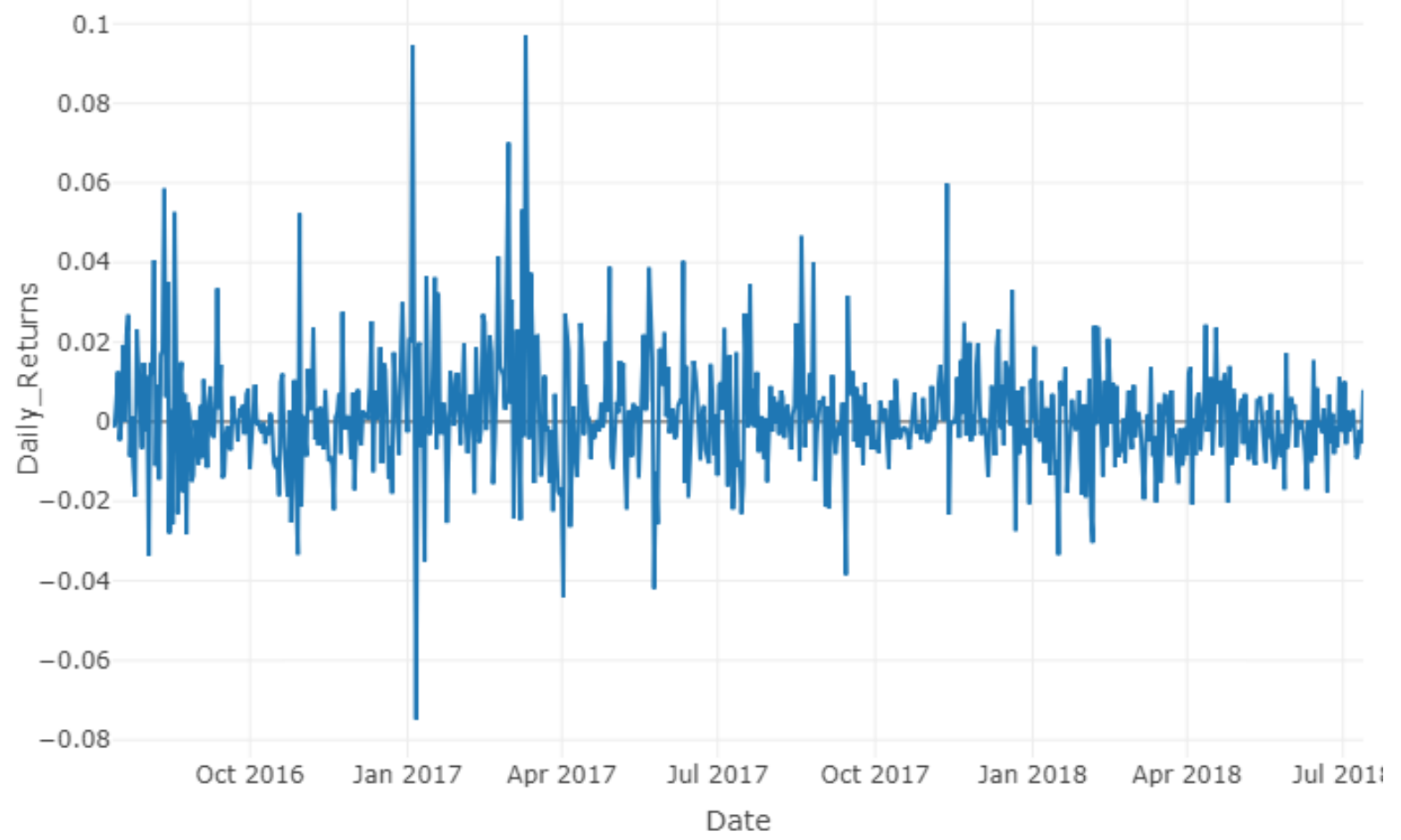

Fig. 6. Figure caption goes here. 
Table 2. Dash coefficients: GARCH( $(1,1)$

\begin{tabular}{lcccc}
\hline & Estimate & Std. Error & t value & $\operatorname{Pr}(>|\mathrm{t}|)$ \\
\hline $\mathrm{mu}$ & -0.0001 & 0.0005 & -0.1822 & 0.8554 \\
omega & 0.0000 & 0.0000 & 3.5344 & 0.0004 \\
alpha1 & 0.2552 & 0.0561 & 4.5481 & 0.0000 \\
beta1 & 0.6819 & 0.0556 & 12.2739 & 0.0000 \\
\hline
\end{tabular}

Dash: $\operatorname{GARCH}(1,1)$ fitted conditional sigma (2 SD)

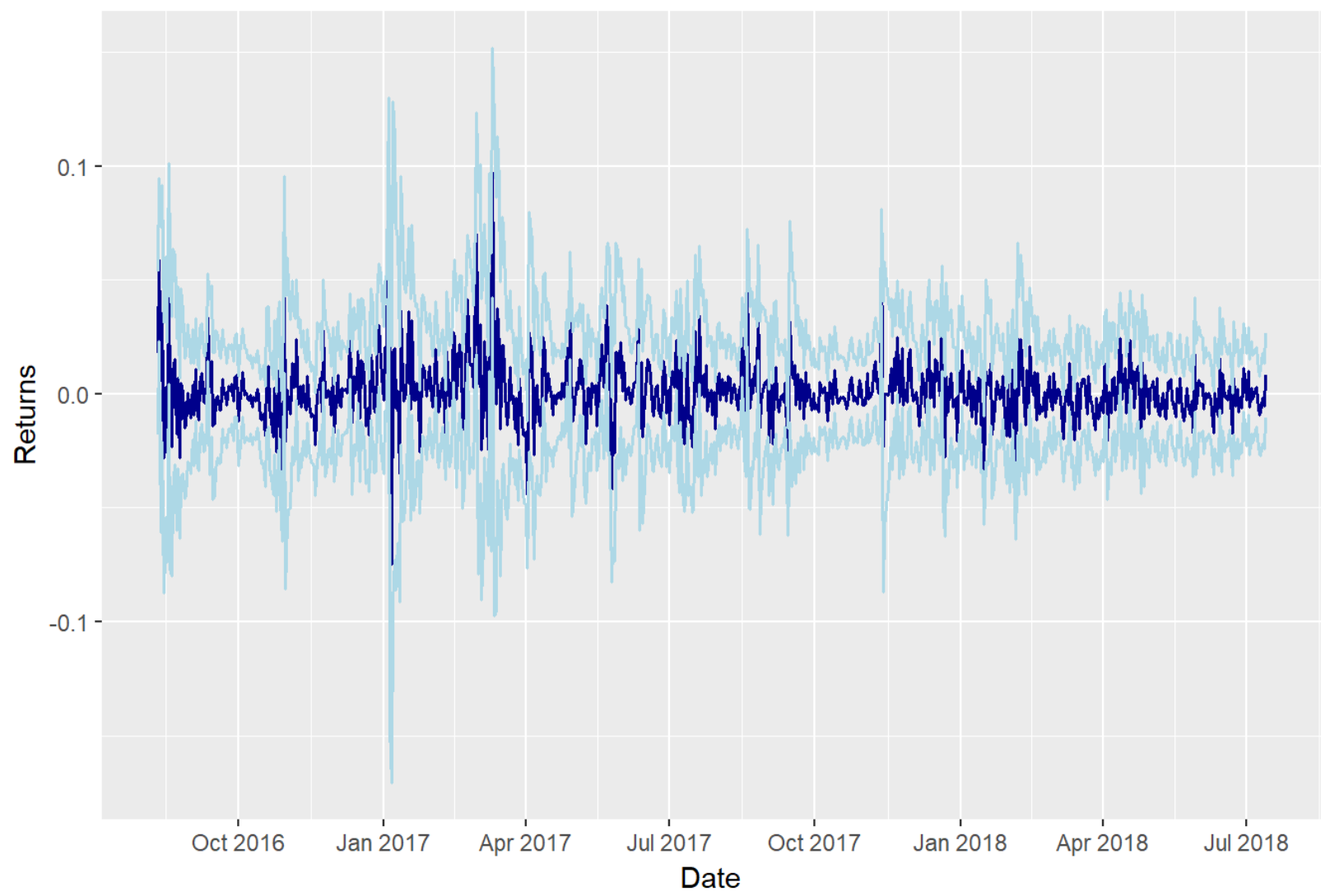

Fig. 7. Figure caption goes here. 


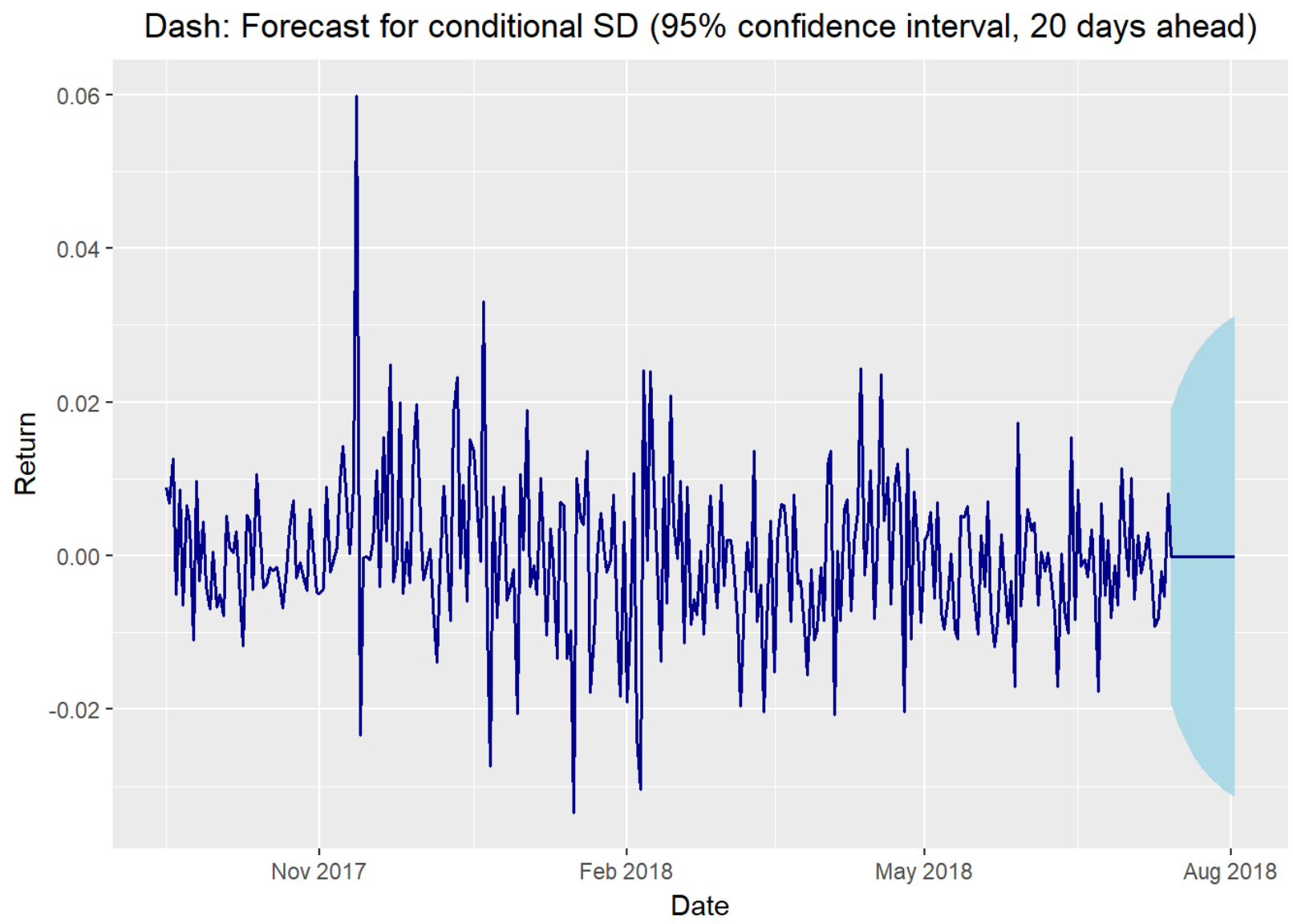

Fig. 8. Figure caption goes here. 


\subsection{BTC}

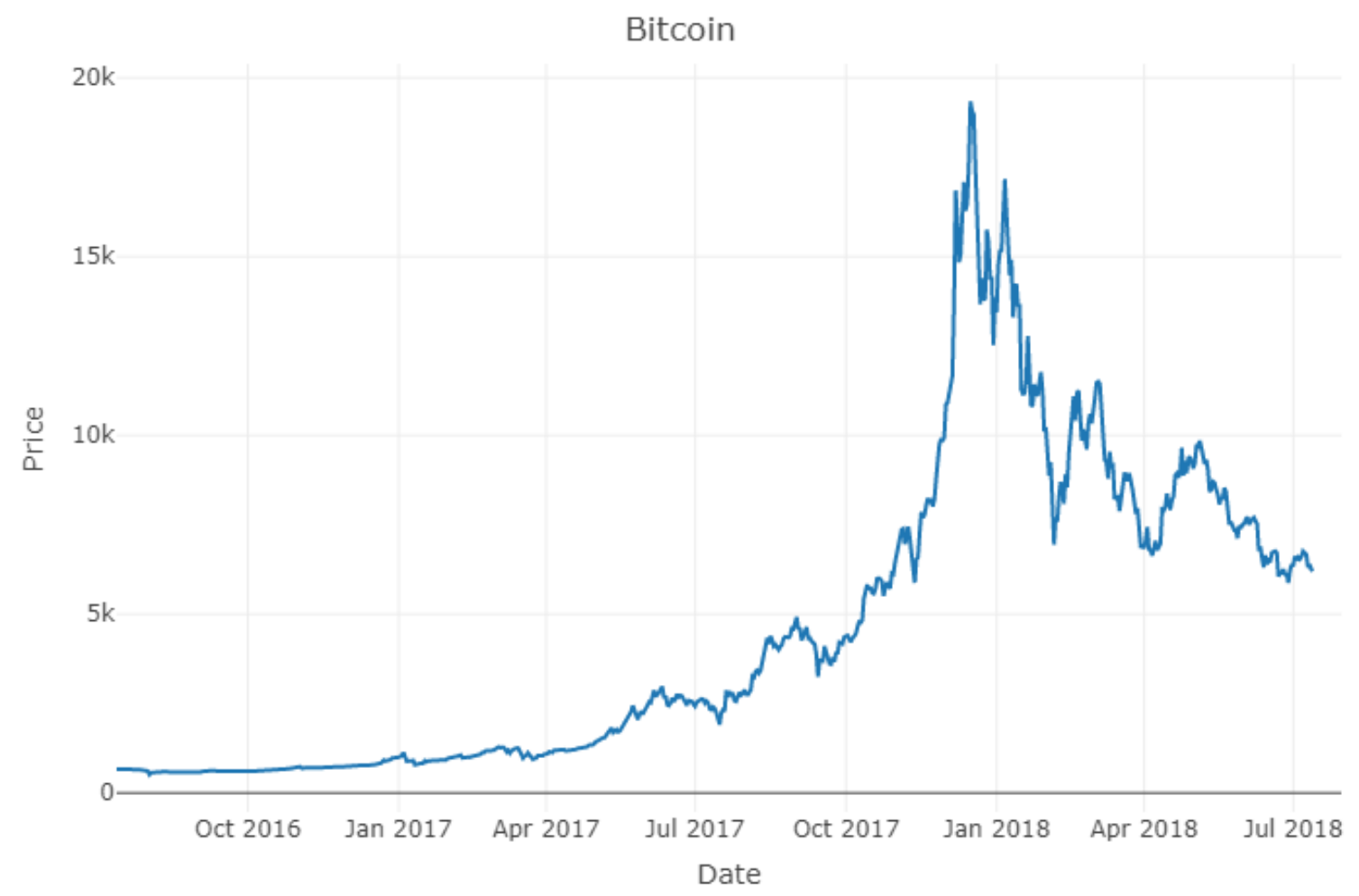

Fig. 9. Figure caption goes here.

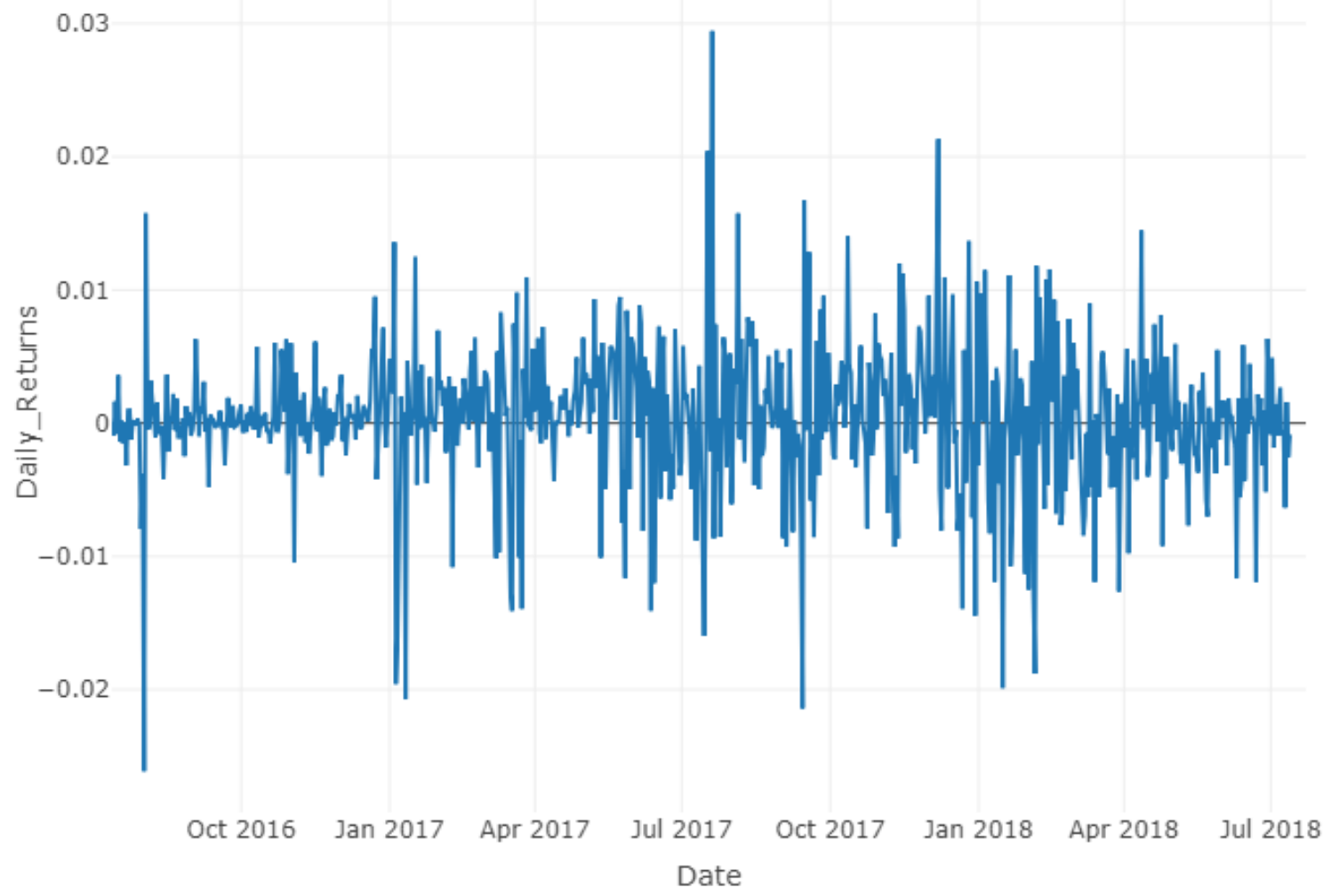


Fig. 10. Figure caption goes here.

Table 3. Bitcoin coefficients: $\operatorname{GARCH}(1,1)$

$\begin{array}{lcccc} & \text { Estimate } & \text { Std. Error } & \mathrm{t} \text { value } & \operatorname{Pr}(>|\mathrm{t}|) \\ \mathrm{mu} & 0.0004 & 0.0002 & 2.8439 & 0.0045 \\ \text { omega } & 0.0000 & 0.0000 & 3.1357 & 0.0017 \\ \text { alpha1 } & 0.2145 & 0.0366 & 5.8632 & 0.0000 \\ \text { beta1 } & 0.7691 & 0.0342 & 22.5001 & 0.0000\end{array}$

Bitcoin: $\mathrm{GARCH}(1,1)$ fitted conditional sigma (2 SD)

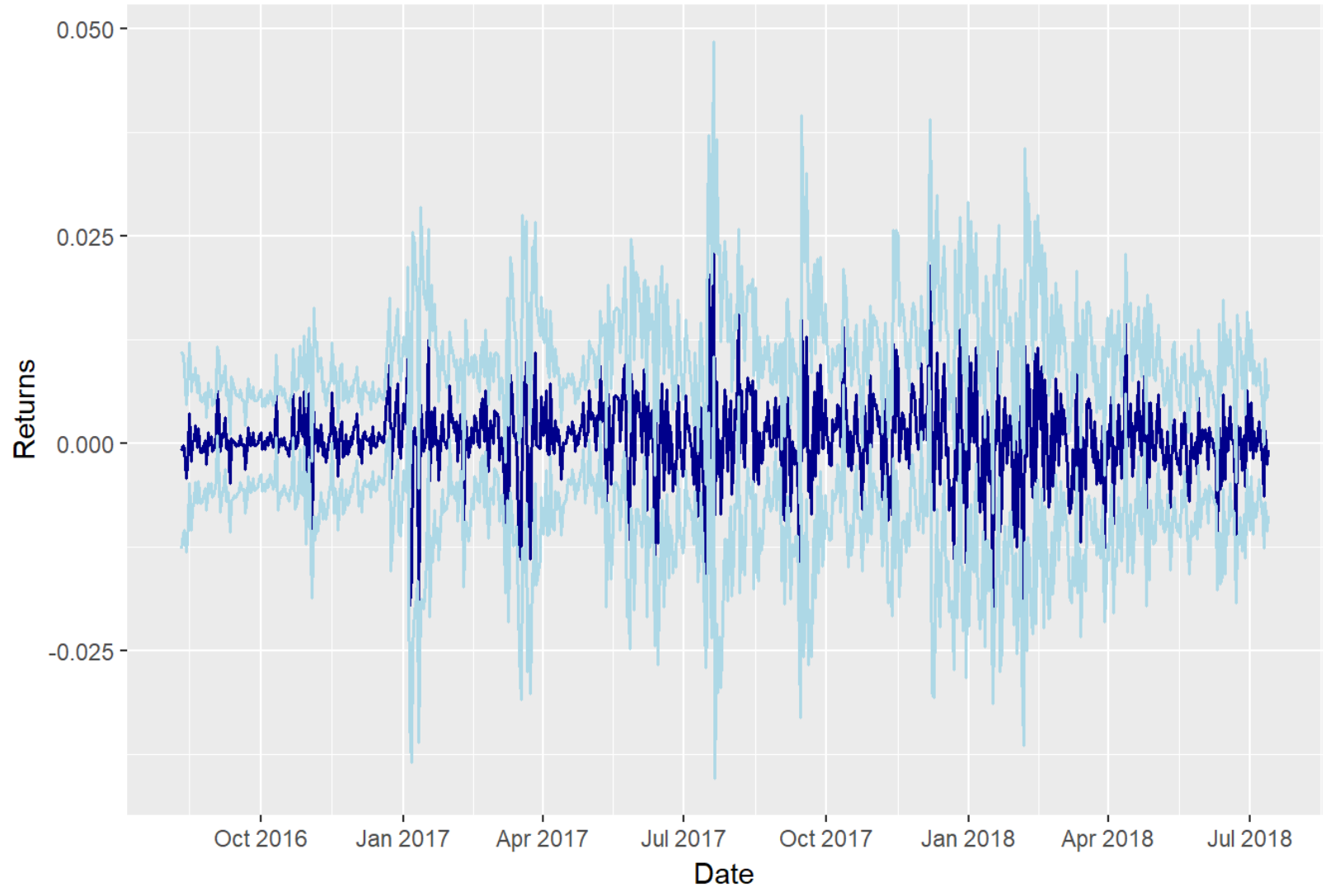

Fig. 11. Figure caption goes here. 
Bitcoin: Forecast for conditional SD (95\% confidence interval, 20 days ahead)

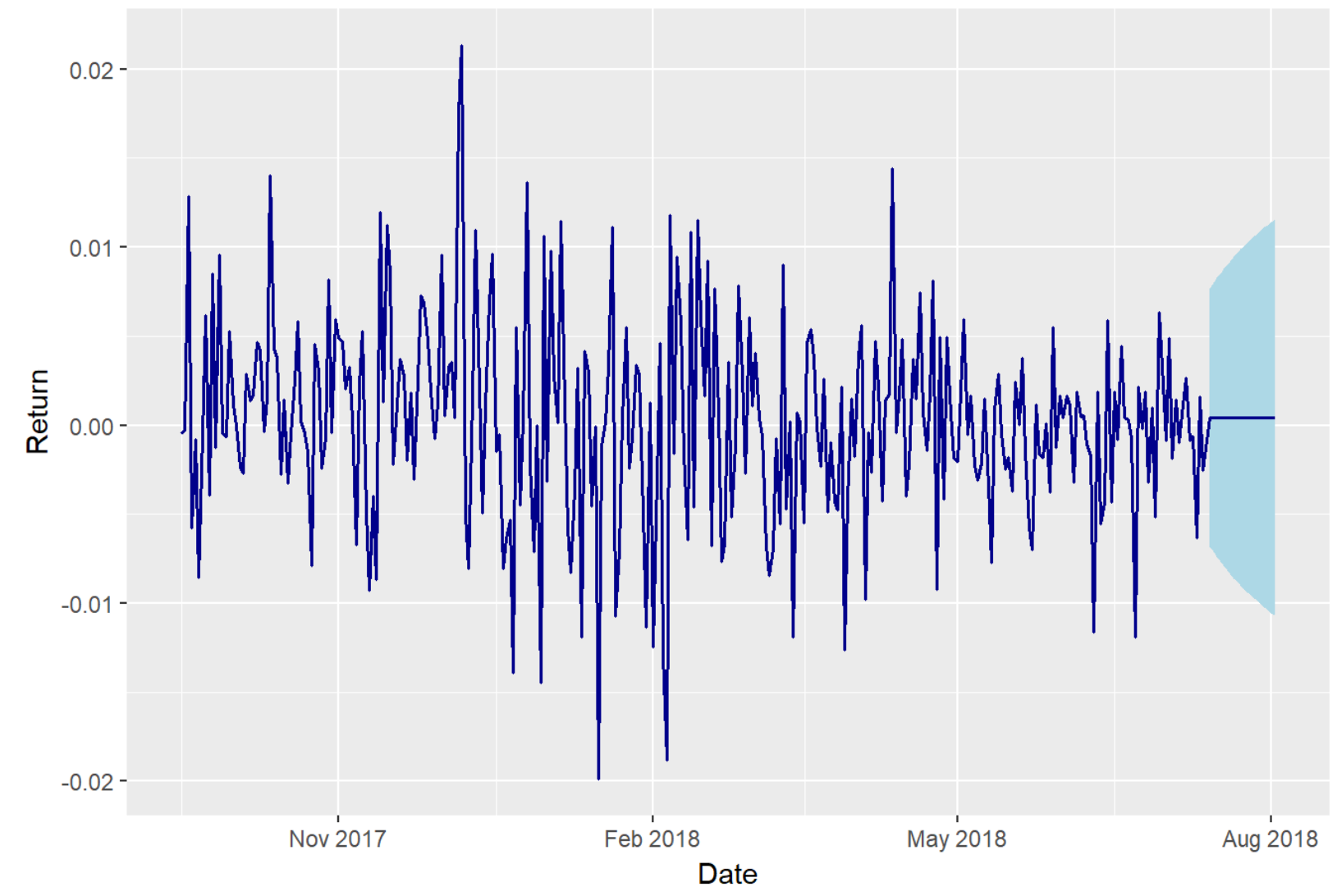

Fig. 12. Figure caption goes here.

\section{The Discussion of Results}

Above, we used GARCH to analyze the volatility of PIVX, Dash, and BTC. The first two charts highlight historical market cap and daily returns. In this discussion, we turn our attention to the third, fourth and fifth charts, named, respectively, 1) Coefficients- $\operatorname{GARCH}(1,1), 2)$ GARCH $(1,1)$ fitted conditional sigma, and 3) Forecast for conditional SD. These three charts highlight only that these three coins will experience only extreme volatility. Specifically, in the fifth chart, the forecast for conditional SD only predicts with 95\% confidence that PIVX, Dash, and BTC will experience only volatility.

These findings, in context, greatly differ from the initial studies of Dyhrberg (2016), who posited that BTC "showed several similarities to gold and the dollar indicating hedging 
capabilities and advantages" (p. 85). Underscored in charts GARCH $(1,1)$ and Forecast for conditional SD, BTC does have a mu, omega, alpha 1 and beta 1 under .05 , but this still is not likely predictive enough for the asset class to be any type of mitigating hedge against either gold or the U.S. dollar. Moreover, the results indicate, much like the work of Walther et al. (2018), that PIVX, Dash, and BTC may only continue to experience volatility.

\subsection{Limitations and Future Research, and Conclusions}

As indicated in the results, both Dash and Bitcoin cohere and standardly fit into a GARCH analysis, yet neither is likely to fund science or higher education, since their respective returns are extremely volatile. Moreover, the work above underscores the complexity of purchasing PIVX, Dash, or Bitcoin as part of an institutional portfolio. Chu, et al. (2017) may not have fully parsed the differences between volatility and valuation models, likely operating under the assumption, as do many financial modeling tools, that cryptocurrencies' values are narrowly intertwined only with arbitrage opportunities related to profits in fiat currency. Chu et al. (2017), while nuanced with a sophisticated literature review and seemingly relevant conclusions, suggested that a need remains for more stringent, systematic literature and methodological reviews. In agreement with Chu et al. (2017), and building upon Baur et al. (2018), this research calls for more detailed valuation metrics in cryptocurrency.

\subsection{The Emic Perspectives: Second Generation Cryptocurrency Valuation Metrics}

In our call for more detailed methodological research, it would not be intellectually rigorous to overlay a first-generation/second-generation narrative onto cryptocurrency valuation metrics. More specifically, GARCH is likely only a first-generation cryptocurrency model that needs to be nuanced to more fully align with the asset class. With that caveat aside, further research likely should incorporate the work of Hayes $(2015,2016,2017)$. To date, Hayes has 
conceptualized a valuation metric centered on Bitcoin that is more aligned with an emic perspective, nuancing the model and covering new ground. Hayes's models represent some of the more advanced framings of BTC, and more broadly, of the ALTcoin markets. Hayes's postulations tend to reflect an insider's vantage point, if not a completely new imagining of valuation metrics. For instance, citing Yermack's (2013) conception of Bitcoin's (BTC)'moneyness' and Gertchev (2013), Harwick (2014), and Bergstra's (2014) contention that BTC is a store of value akin to gold, Hayes (2015) proffered a number of valuation formulas, from a metric for BTC mining to a formula for ALTcoin values. In later work, Hayes (2017) accounted for the value inherent in cryptocurrency by parsing out issues that are not applicable and centering on deploying metrics that focused on the cost of mining, the intersection of software and network architecture, the acceptance of cryptocurrency as a means of exchange, and whether a currency was widely available on multiple exchanges. The next modeling for cryptocurrency valuation models likely needs to employ Hayes's $(2015,2017)$ modeling that is a hybrid of the more traditional time-series modeling, primarily because this type of modeling more thoroughly represents the cryptocurrency markets.

\subsection{The Etic: First-Generation Cryptocurrency Valuation Metrics}

Generally, the first generation of cryptocurrency valuation metrics should be viewed as etic approaches to understanding a new asset class. Extending Pike's (1973) theoretical framework, built upon by numerous qualitative researchers such as Emdin (2006) and Kincheloe and Tobin (2009), the etic and emic refer, respectively, to outsider and insider observational perspectives. In this case, this first generation of etic valuation models should be viewed as traditional economists overlaying industry-standard tools in ways that did not altogether fit. For instance, the etic is perceived in the straightforward deployment of GARCH as a tool to measure 
volatility and price targets. Specifically, the appropriation and extension of GARCH tends to confine the multivariate valuation metrics needed to understand BTC and alternative coins (ALTcoins) to an overly formulaic account, not fully accounting for the complex of the ecosphere or its tendency to root currency development and deployment within modes of thought from the Austrian School.

\subsection{Moving Away from Etic Models}

Dyhrberg (2016), Gronwald (2014), and Katsiampa (2017) all deployed GARCH to frame BTC's and to a lesser degree ALTcoins' volatility metrics to determine whether the assets were overbought or oversold. However, Dyhrberg (2016), Gronwald (2014), and Katsiampa (2017), representing the most highly cited authors who employed GARCH specific to cryptocurrency, used this measure while generally overlooking the nuances of this asset class. While GARCH admittedly has many iterations and new models, the deployment of a GARCHonly analysis nevertheless overlooks Greer's (1997) contention that assets within a class share some fundamental characteristics, and some of these characteristics are distinct to cryptocurrencies. Burniske and White (2017), for instance, noted that BTC is unique in that it is not affected by price movements in other asset classes, meaning that, despite volatility within cryptocurrency, there are no price correlations to other asset classes. Burniske and Tartar (2017) extended the initial framework by including in valuation the number of outstanding coins, the velocity of the currency, and the price and quality of the community supporting the currency. Considering both Burniske and White (2017) and Burniske and Tartar (2017), who provided emic perspectives, the initial GARCH cryptocurrency models may be too focused on conditional standard deviation and volatility clustering to provide long-term perspectives on price. GARCH modeling may therefore be more helpful if nuances are made to better reflect the distinctiveness 
of cryptocurrencies. Although various GARCH analyses arguably represent the more advanced modeling in this area, there are still a number of methodological problems, even in the most sophisticated work, related to using only this type of modeling.

Although a comprehensive scoping of GARCH analysis and cryptocurrency is beyond the scope of this paper, this work underscores that the time has come for full-length methodological reviews to be published on both cryptocurrency volatility and valuation models. As cryptocurrency matures as an asset class, both the scholarly literature and methodological reviews need to advance and broaden their respective scopes. Chu et al. (2017), for example, recently argued that IGARCH and GJRGARCH models are the best tools for modeling the volatility in the largest and most popular cryptocurrencies. Chu et al. (2017) persuasively highlighted the need to nuance metrics and deploy different models in order to more accurately gage valuation of cryptocurrencies.

\subsection{Next Steps}

In spite of its sophistication and emic perspectives, Hayes's $(2015,2017)$ work may be insufficient on its own to the task of appraising which cryptocurrency can be deployed for science and higher education funding, since an accurate evaluation must consider not only valuation metrics but also an enacted network effect. Hayes's (2017) work, in particular, is a production framework, rather any type of valuation metric, although this work has been widely cited as the latter (Indera et al., 2017; Parham, 2017). The predictable cost of Bitcoin. Moving the valuable insights of Hayes forward, Balcilaret al. (2017) articulated a model for BTC returns, accounting for volatility, by employing a nonparametric causality-in-quantiles test. Balcilar et al. (2017) underscored the significance of modeling nonlinearity and the need to calculate for complexities of tail behavior related to causal relationships. More precisely, Balcilar et al. (2017) 
noted that a straightforward conditional distribution is not sufficiently complex to predict BTC's volatility. Balcilar et al. (2017) thereby greatly improved the valuation metrics for cryptocurrency by providing a methodological bridge that conjoined valuation with network effect theory. While Hayes (YEAR) improved on the various GARCH-only models of analysis, his work should likely be blended with consideration of network effect in order to construct tenable funding mechanisms. As a result, hybrid methodologies must be advanced. Peterson (2018) provided an overview of network models, which was modified by Vliet (2018).

Collectively, Balcilar et al. (2017), Hayes (2015), and others, may provide the beginnings of new methodological work for cryptocurrency valuation metrics.

\subsection{Returning to Funding Science and Education}

In previous work, we described how a group of education researchers and Wall Street bankers developed a fund that generated significant alpha return, in spite of the market's volatility. Our first model was developed to serve as an alternative funding mechanism for scientific research. As the market has developed this model, although initially successful, is insufficiently complex to enact now. In our first cryptocurrency model, we focused specifically on funding basic scientific research. We continue to see the vision of ALTcoins to fund science and education, yet it will likely more fully cohere with Lehner and Ziegler (2018) and not our initial framework.

\section{References}

Aud, S., Hussar, W., Planty, M., Snyder, T., Bianco, K., Fox, M.A., Frohlich, L., Kemp, J., Drake, L., 2010. The condition of education (NCES 2010-028). https://eric.ed.gov/?id=ED509940 (Accessed August 17, 2018).

Balcilar, M., Bouri, E., Gupta, R., Roubaud, D., 2017. Can volume predict Bitcoin returns and 
volatility? A quantiles-based approach. Econ. Model. 64, 74-81.

https://doi.org/10.1016/j.econmod.2017.03.019 (Accessed August 17, 2018).

Barr, M.J., McClellan, G.S., 2018. Budgets and Financial Management in Higher Education, third ed. Jossey-Bass, San Francisco.

Baur, D.G., Dimpfl, T., Kuck, K., 2018. Bitcoin, gold and the US dollar: A replication and extension. Finance Res. Lett. 25, 103-110. https://doi.org/10.1016/j.frl.2017.10.012 (Accessed August 17, 2018).

Bollerslev, T., Engle, R.F., Wooldridge, J.M., 1988. A capital asset pricing model with timevarying covariances. J. Polit. Econ. 96, 116-131.

Burniske, C., Tatar, J., 2017. Cryptoassets: The Innovative Investor's Guide to Bitcoin and Beyond. McGraw Hill Professional, New York.

Burniske, C., White, A., 2017. Bitcoin: Ringing the bell for a new asset class. https://research.ark-invest.com/hubfs/1_Download_Files_ARKInvest/White_Papers/Bitcoin-Ringing-The-Bell-For-A-New-Asset-Class.pdf (Accessed August 17, 2018).

Byun, S.J., Jeon, B.H., Min, B., Yoon, S.-J., 2015. The role of the variance premium in Jump GARCH option pricing models. J. Bank. Finance 59, 38-56.

Christensen, C.M., Eyring, H.J., 2011. The Innovative University: Changing the DNA of Higher Education from the Inside Out. Jossey-Bass, San Francisco.

Christensen, C.M., Horn, M.B., Soares, L., Caldera, L., 2011. Disrupting college: How disruptive innovation can deliver quality and affordability to postsecondary education. https://www.americanprogress.org/issues/economy/reports/2011/02/08/9034/disruptingcollege/ (Accessed August 17, 2018). 
Christman, D.E., 2000. Multiple realities: Characteristics of loan defaulters at a two-year public institution. Community Coll. Rev. 27(4), 16.

Chu, J., Chan, S., Nadarajah, S., Osterrieder, J., 2017. GARCH modelling of cryptocurrencies. J. Risk Financ. Manage., 10(4), 17.

Cockrell School of Engineering, University of Texas, 2014. Metcalfe's Law After 40 Years of Ethernet. https://www.youtube.com/watch?v=f6CJA421aUo (Accessed August 17, 2018).

College Board, 2011a. The College Completion Agenda: 2011 Progress Report. College Board Advocacy \& Policy Center, Washington, DC.

College Board, 2011b. Trends in College Pricing 2011. College Board, Washington, DC.

Cunningham, A., Kienzl, G., 2011. Delinquency: The Untold Story of Student Loan Borrowing. Institute for Higher Education Policy, Washington, DC.

Deming, D., Goldin, C., Katz, L., 2012. The for-profit postsecondary school sector: Nimble critters or agile predators. J. Econ. Perspect. 26, 139-164.

Dillon, E., Carey, K., 2009. Drowning in Debt: The Emerging Student Loan Crisis. Education Sector, Washington, DC.

Dillon, E., Smiles, R., 2010. Lowering Student Loan Default Rates: What One Consortium of Historically Black Institutions Did to Succeed. Education Sector, Washington, DC.

Dyhrberg, A. H., 2016. Bitcoin, gold and the dollar-A GARCH volatility analysis. Finance Res. Lett. 16, 85-92.

Dynarski, M., 1994. Who defaults on student loans? Findings from the national postsecondary student aid study. Econ. Educ. Rev. 13(1), 55-68.

Emdin, C., 2006. Beyond coteaching: Power dynamics, cosmopolitanism and the psychoanalytic 
dimension. Forum Qual. Soc. Res. 7(4). http://dx.doi.org/10.17169/fqs-7.4.189 (Accessed August 17, 2018).

Emdin, C., 2010. Urban Science Education for the Hip-Hop Generation. Sense, Boston.

Emdin, C., Lehner, E., 2006. Situating cogenerative dialogue in a cosmopolitan ethic. Forum Qual. Soc. Res. 7(2). http://dx.doi.org/10.17169/fqs-7.2.125 (Accessed August 17, 2018).

Engle, R.F., Bollerslev, T., 1986. Modelling the persistence of conditional variances. Econom. Rev. 5(1), 1-50.

Gilchrist, H., 2018. Higher education as a human right. https://ssrn.com/abstract=3100852 (Accessed August 17, 2018).

Gittleson, K., Usher, B., 2017. Higher education for refugees. Stanford Soc. Innov. Rev. https://ssir.org/articles/entry/higher_education_for_refugees (Accessed August 17, 2018).

Gladieux, L., 1995. Federal student aid policy: A history and an assessment, in: Financing Postsecondary Education: The Federal Role. http://www2.ed.gov/offices/OPE/PPI/FinPostSecEd/gladieux.html (Accessed August 17, 2018).

Gladieux, L., Perna, L., 2005. Borrowers who drop out: A neglected aspect of the college student loan trend. http://www.highereducation.org/reports/borrowing/index.shtml (Accessed August 17, 2018).

Greene, L.L., 1989. An economic analysis of student loan default. Educ. Eval. Policy Anal. 11(1), 61.

Greenwood, D.J., 2008. Theoretical research, applied research, and action research, in: Hale, C.R. (Ed.), Engaging Contradictions: Theory, Politics, and Methods of Activist Scholarship. University of California Press, Berkeley, pp. 319-340. 
Greenwood, J.D., Levin, M., 2011. Introduction to Action Research, second ed. Sage, Thousand Oaks, CA.

Gronwald, M., 2014. The economics of bitcoins: Market characteristics and price jumps. https://ideas.repec.org/p/ces/ceswps/_5121.html (Accessed August 17, 2018).

Hayes, A., 2015. What factors give cryptocurrencies their value: An empirical analysis. https://papers.ssrn.com/sol3/papers.cfm?abstract_id=2579445 (Accessed August 17, 2018).

Hayes, A.S., 2017. Cryptocurrency value formation: An empirical study leading to a cost of production model for valuing bitcoin. Telemat. Inform. 34, 1308-1321.

Hillman, N.W., 2014. College on credit: A multilevel analysis of student loan default. Rev. High. Ed. 37, 169-195.

Indera, N.I., Yassin, I.M., Zabidi, A., Rizman, Z.I., 2017. Non-linear autoregressive with exogeneous input (NARX) Bitcoin price prediction model using PSO-optimized parameters and moving average technical indicators. Rev. Sci. Fondam. Appl. 9(3S), 791-808.

Kaplan, E., 2004. With God on their side: How Christian fundamentalists trampled science, policy, and democracy in George W. Bush's White House. SIECUS Rep. 32(4), 4.

Katsiampa, P., 2017. Volatility estimation for Bitcoin: A comparison of GARCH models. Econ. Lett. 158, 3-6.

Kazin, M., 2016. Trump and American populism: Old whine, new bottles. Foreign Aff. 95, 17.

Kesterman, F. (2006). Student borrowing in America: metrics, demographics, default aversion strategies. J. Stud. Financ. Aid 36(1), 34-52.

Kincheloe, J.L., Tobin, K., 2009. The much exaggerated death of positivism. Cult. Stud. Sci. 
Educ. 4, 513-528. https://dx.doi.org/10.1007/s11422-009-9178-5 (Accessed August 17, 2018).

Knapp, L.G., Seaks, T.G., 1992. An analysis of the probability of default on federally guaranteed student loans. Rev. Econ. Stat. 74, 404-411.

Leachman, M., Masterson, K., Wallace, M., 2016. After nearly a decade, school investments still way down in some states. https://www.cbpp.org/research/state-budget-and-tax/afternearly-a-decade-school-investments-still-way-down-in-some-states (Accessed August 17, 2018).

Lehner, E., Finley, K., 2016. Should the New England Education Research Organization start a journal in the age of audit culture? Reflections on academic publishing, metrics, and the new academy. https://academicworks.cuny.edu/bx_pubs/15/(Accessed August 17, 2018).

Lehner, E., Hunzeker, D., Ziegler, J.R., 2018. Funding science with science: Cryptocurrency and independent academic research funding. Ledger, 2. https://ledger.pitt.edu/ojs/index.php/ledger/article/view/108 (Accessed August 17, 2018).

Lehner, E., Ziegler, J.R., 2017. Knowledge systems and the colonial legacies in African science education. https://academicworks.cuny.edu/bx_pubs/36/ (Accessed August 17, 2018).

Levin, M., Greenwood, D.J., 2017. Creating a New Public University and Reviving Democracy. Berghahn, New York.

Luke, D.A., Sarli, C.C., Suiter, A.M., Carothers, B.J., Combs, T.B., Allen, J.L., Beers, C.E., Evanoff, B.A., 2018. The translational science benefits model: A new framework for assessing the health and societal benefits of clinical and translational sciences. Clin. Transl. Sci. 11, 77-84.

McMahon, W.W., 2009. Higher Learning, Greater Good: The Private and Social Benefits of 
Higher Education. Johns Hopkins University, Baltimore.

Mead, W.R., 2017. The Jacksonian revolt: American populism and the liberal order. Foreign Aff. $96,2$.

National Center for Education Statistics, 2010. The Condition of Education 2010. Indicator 17. National Center for Education Statistics, Washington, DC.

Parham, R., 2017. The predictable cost of Bitcoin. https://papers.ssrn.com/sol3/papers.cfm?abstract_id=3080586 (Accessed August 17, 2018).

Peters, M.A., 2018. The end of neoliberal globalisation and the rise of authoritarian populism. Educ. Philos. Theory 50, 323-325.

Pike, K.L., 1967. Language in Relation to a Unified Theory of the Structure of Human Behavior, 2nd rev. ed. Mouton, The Hague, Netherlands.

Reardon, S., Tollefson, J., Witze, A., Ross, E., 2017. Trump redoubles plan to slash science spending. Nature. https://www.nature.com/polopoly_fs/1.22036.1496251823!/menu/main/topColumns/tope $\mathrm{ftColn/pdf/nature.2017.22036.pdf?origin=ppub}$

Rickman, D.S., Wang, H., 2018. Two tales of two US states: Regional fiscal austerity and economic performance. Reg. Sci. Urban Econ. 68, 46-55.

Walther, T., Klein, T., Thu, H. P., 2018. Bitcoin is not the new gold: A comparison of volatility, correlation, and portfolio performance. Int. Rev. Financ. Anal. 59, 105-116. 